\title{
Evaluation of Agreement of Overweight Screening Criteria in Adolescents: Korean National Health and Nutrition Examination Surveys
}

\author{
Ji Yeon Han', Sochung Chung ${ }^{1,2, *}$ \\ ${ }^{1}$ Department of Pediatrics, Konkuk University Medical Center, Seoul; ${ }^{2}$ Department of Pediatrics, Konkuk University School of Medicine, Seoul, Korea
}

Background: The increasing prevalence of overweight children and childhood obesity has led to early development of obesity-related diseases, including diabetes. Screening tests for type 2 diabetes in children indicate overweight as a major risk factor. Three overweight screening criteria have been considered: body mass index (BMI) $>85$ th percentile (overweight 1, OW1), weight for height $>85$ th percentile (OW2), and weight $>120 \%$ of ideal for height $(\mathrm{OW} 3)$. This study was conducted to evaluate the agreement in these screening criteria and the impact of increased use of screening methods.

Methods: Data were obtained from 965 Korean adolescents (521 boys and 444 girls). The subjects were classified into overweight and normal weight groups by the three above criteria. The agreement between criteria was evaluated using Cohen's kappa value. Furthermore, we studied the relationships between the criteria and parameters of height, weight, BMl, and z score, based on the 2007 Korean growth chart.

Results: Totals of 188, 139, and 115 adolescents were classified as OW1, OW2, and OW3, respectively. The kappa values were $0.798,0.710$, and 0.891 for OW1 and OW2, OW1 and OW3, and OW2 and OW3, respectively. Weight, weight-z, BMl, and BMl-z were greater among subjects in all overweight groups compared to the normal weight group. However, the heights of the subjects did not differ between the three groups.

Conclusion: Active assessment of overweight status using OW1 could be improved by including more adolescents and focusing on the variability of individual growth and disease risk, even though substantial agreement was observed among the three overweight screening criteria.

Key words: Overweight, Obesity, Body mass index, Adolescent, Growth

\author{
Received January 26, 2021 \\ Reviewed May 12, 2021 \\ Accepted May 12, 2021 \\ *Corresponding author \\ Sochung Chung \\ https://orcid.org/0000-0002-7655-2691 \\ Department of Pediatrics, Konkuk \\ University Medical Center, Konkuk \\ University School of Medicine, \\ 120-1 Neungdong-ro, Gwangjin-gu, \\ Seoul 05030, Korea \\ Tel: +82-2-2030-7553 \\ Fax: +82-2-2030-7748 \\ E-mail: scchung@kuh.ac.kr
}

\section{INTRODUCTION}

The worldwide prevalence of childhood obesity has increased over the past three decades, including in Korea. ${ }^{1,2}$ The increasing prevalence of childhood obesity has led to obesity-related comorbid diseases, including diabetes, at an early age. ${ }^{3.5}$ Screening tests for type 2 diabetes in asymptomatic children test for obesity plus any two of the following risk factors: family history of type 2 diabetes, race/ ethnicity, or signs of insulin resistance or conditions associated with insulin resistance such as acanthosis nigricans, hypertension, dys- lipidemia, or small for-gestational-age birth weight. ${ }^{6}$ According to the American Diabetes Association, three overweight criteria are considered in this screening test: body mass index $(\mathrm{BMI})>85$ th percentile for age and sex (overweight $1, \mathrm{OW} 1$ ), weight for height $>85$ th percentile (OW2), and weight $>120 \%$ of ideal for height (OW3). ${ }^{7}$ The present study was conducted to evaluate agreement in the three screening criteria and the impact of increased use of screening methods. In addition, this study aimed to minimize the number of affected children overlooked during the overweight screening process. 


\section{METHODS}

\section{Subjects}

This study was performed using data from the Fourth and Fifth Korea National Health and Nutrition Examination Surveys conducted by the Korea Centers for Disease Control and Prevention, including a total of 965 adolescents ( 521 boys and 444 girls) from 10 to 18 years of age. Details of the subjects have been described in a previous study. ${ }^{8}$ The subjects were classified into overweight groups based on criteria. Subjects were included in the normal weight group if no criterion was met. The Institutional Review Board of Konkuk University Medical Center (IRB No. 2020-11045) approved this study. Owing to the retrospective design, the requirement for informed consent was waived.

\section{Anthropometric measurements}

The weight (WT) and height (HT) of the participants were measured in light clothing and without shoes. WT was measured with a digital scale (GL-6000-20; CASKOREA, Seoul, Korea) to the nearest $0.1 \mathrm{~kg}$, and HT was measured to the nearest $0.1 \mathrm{~cm}$ with a stadiometer (SECA 225; SECA Deutschland, Hamburg, Germany). BMI was calculated as weight $(\mathrm{kg}) /$ height $^{2}\left(\mathrm{~m}^{2}\right)$. Growth status as measured by HT, WT, and BMI and z scores based on age and sex were based on the 2007 Korean growth chart. ${ }^{9}$

\section{Statistical analysis}

Data are expressed as mean \pm standard deviation. Inter-group comparisons of the assessments were performed using t-test, and agreement was evaluated using Cohen's kappa values to analyze the

Table 1. Characteristics of the study populations

\begin{tabular}{lccc}
\hline Variable & Boy $(\mathrm{n}=521)$ & Girl $(\mathrm{n}=444)$ & Total $(\mathrm{n}=965)$ \\
\hline Age $(\mathrm{yr})$ & $13.5 \pm 2.6$ & $13.6 \pm 2.5$ & $13.6 \pm 2.5$ \\
$\mathrm{HT}(\mathrm{cm})$ & $161.8 \pm 13.2$ & $156.7 \pm 8.2$ & $159.5 \pm 11.4$ \\
$\mathrm{WT}(\mathrm{kg})$ & $54.9 \pm 15.0$ & $49.6 \pm 11.0$ & $52.4 \pm 13.6$ \\
$\mathrm{BMI}\left(\mathrm{kg} / \mathrm{m}^{2}\right)$ & $20.7 \pm 3.8$ & $20.0 \pm 3.4$ & $20.4 \pm 3.7$ \\
$\mathrm{HTz}$ & $0.74 \pm 1.06$ & $0.66 \pm 1.05$ & $0.70 \pm 1.06$ \\
$\mathrm{WTz}$ & $0.37 \pm 1.07$ & $0.35 \pm 1.04$ & $0.36 \pm 1.06$ \\
$\mathrm{BMlz}$ & $0.06 \pm 1.12$ & $0.09 \pm 1.05$ & $0.07 \pm 1.09$ \\
\hline
\end{tabular}

Values are presented as mean \pm standard deviation.

$H T$, height; WT, weight; BMI, body mass index; $H T z$, z score of $H T$; $W T z, z$ score of $W T$; $\mathrm{BMlz}$, z score of BMl. consistency of each criterion. The significance level for each comparison was set at $P<0.05$. All analysis was performed using SPSS ver. 17.0 (SPSS Inc., Chicago, IL, USA).

\section{RESULTS}

A total of 965 adolescents constituted the study population. The characteristics of each group according to sex are shown in Table 1. The mean HT, WT, and BMI of the subjects were $159.5 \mathrm{~cm}, 52.4 \mathrm{~kg}$, and $20.4 \mathrm{~kg} / \mathrm{m}^{2}$, respectively, and their z scores of HT (HTz), WT (WTz), BMI (BMIz) were 0.70, 0.36, and 0.07. Totals of 188 (108

Table 2. Comparisons of subjects in the overweight and normal weight groups and between overweight groups

\begin{tabular}{|c|c|c|c|c|}
\hline \multirow{2}{*}{ Variable } & \multicolumn{2}{|c|}{ Boy } & \multicolumn{2}{|c|}{ Girl } \\
\hline & OW1 $(n=108)$ & NW1 (n=413) & OW1 $(n=80)$ & NW1 $(n=364)$ \\
\hline Age (yr) & $13.2 \pm 2.5$ & $13.6 \pm 2.6$ & $13.4 \pm 2.5$ & $13.6 \pm 2.5$ \\
\hline $\mathrm{HT}(\mathrm{cm})$ & $161.8 \pm 13.1$ & $161.8 \pm 13.2$ & $157.9 \pm 7.6$ & $156.4 \pm 8.3$ \\
\hline WT (kg) & $69.2 \pm 15.7^{*}$ & $51.1 \pm 12.3$ & $63.2 \pm 11.3^{*, \pm}$ & $46.6 \pm 8.4$ \\
\hline $\mathrm{BMI}\left(\mathrm{kg} / \mathrm{m}^{2}\right)$ & $26.1 \pm 2.6^{*, \pm}$ & $19.2 \pm 2.5$ & $25.2 \pm 3.2^{* \text {, }}$ & $18.9 \pm 2.1$ \\
\hline $\mathrm{HTz}$ & $0.98 \pm 1.10^{*}$ & $0.68 \pm 1.03$ & $0.90 \pm 1.18^{*, \pm}$ & $0.61 \pm 1.02$ \\
\hline WTz & $1.69 \pm 0.56^{*}$ & $0.02 \pm 0.89$ & $1.79 \pm 0.62^{*}$ & $0.03 \pm 0.83$ \\
\hline \multirow[t]{2}{*}{$\mathrm{BMlz}$} & $1.57 \pm 0.39^{*, t, \pm}$ & $-0.34 \pm 0.88$ & $1.67 \pm 0.52^{*, \pm}$ & $-0.26 \pm 0.79$ \\
\hline & OW2 (n=81) & NW2 (n=440) & OW2 (n=58) & NW2 (n=386) \\
\hline Age (yr) & $13.4 \pm 2.7$ & $13.6 \pm 2.5$ & $14.1 \pm 2.3$ & $13.5 \pm 2.5$ \\
\hline $\mathrm{HT}(\mathrm{cm})$ & $161.7 \pm 13.6$ & $161.8 \pm 13.1$ & $158.2 \pm 7.0$ & $156.5 \pm 8.4$ \\
\hline WT (kg) & $71.3 \pm 16.4^{*}$ & $51.9 \pm 12.6$ & $66.0 \pm 11.0^{*}$ & $47.1 \pm 8.7$ \\
\hline $\mathrm{BMI}\left(\mathrm{kg} / \mathrm{m}^{2}\right)$ & $26.8 \pm 2.6^{*}$ & $19.5 \pm 2.7$ & $26.2 \pm 3.1^{*}$ & $19.1 \pm 2.2$ \\
\hline $\mathrm{HTz}$ & $0.81 \pm 1.16$ & $0.75 \pm 1.04$ & $0.53 \pm 1.12$ & $0.69 \pm 1.04$ \\
\hline WTz & $1.75 \pm 0.62^{*}$ & $0.11 \pm 0.93$ & $1.78 \pm 0.72^{*}$ & $0.13 \pm 0.91$ \\
\hline \multirow[t]{2}{*}{ BMlz } & $1.70 \pm 0.36^{*}$ & $-0.25 \pm 0.93$ & $1.80 \pm 0.54^{*}$ & $-0.17 \pm 0.85$ \\
\hline & OW3 $(n=75)$ & NW3 (n= 446) & OW3 $(n=40)$ & NW3 $(n=404)$ \\
\hline Age (yr) & $13.4 \pm 2.7$ & $13.6 \pm 2.5$ & $14.3 \pm 0.4$ & $13.5 \pm 2.5$ \\
\hline $\mathrm{HT}(\mathrm{cm})$ & $161.0 \pm 13.8$ & $161.9 \pm 13.1$ & $157.4 \pm 6.7$ & $156.6 \pm 8.4$ \\
\hline WT (kg) & $71.1 \pm 17.0^{*}$ & $52.2 \pm 12.8$ & $67.9 \pm 11.9^{*}$ & $47.8 \pm 9.1$ \\
\hline $\mathrm{BMI}\left(\mathrm{kg} / \mathrm{m}^{2}\right)$ & $26.9 \pm 2.7^{*}$ & $19.6 \pm 2.8$ & $27.2 \pm 3.2^{*}$ & $19.3 \pm 2.4$ \\
\hline $\mathrm{HTz}$ & $0.79 \pm 1.18$ & $0.73 \pm 1.03$ & $0.33 \pm 1.11^{*}$ & $0.70 \pm 1.05$ \\
\hline WTz & $1.77 \pm 0.64^{*}$ & $0.13 \pm 0.94$ & $1.90 \pm 0.76^{*}$ & $0.20 \pm 0.94$ \\
\hline BMlz & $1.73 \pm 0.36^{*}$ & $-0.23 \pm 0.94$ & $2.00 \pm 0.53^{*}$ & $-0.10 \pm 0.89$ \\
\hline
\end{tabular}

Values are presented as mean \pm standard deviation. OW1 is a group with $\mathrm{BMI}>85$ th percentile for age and sex, OW2 is a group with weight for height $>85$ th percentile, and OW3 is a group with weight $>120 \%$ of ideal for height. NW is a group that does not meet any of the overweight criteria.

* Statistically significant $P<0.05$ between $\mathrm{OW}$ and NW; 'Statistically significant

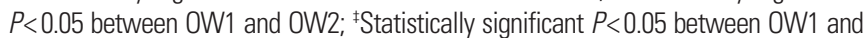
OW3. There was no significant difference between $\mathrm{OW} 2$ and $\mathrm{OW} 3$.

OW, overweight; NW, normal weight; $H T$, height; WT, weight; BMl, body mass index; $H T z$, z score of $H T$; $W T z$, z score of $W T$; BMlz, z score of BMI. 
boys and 80 girls), 139 ( 81 boys and 58 girls), and 115 (75 boys and 40 girls) adolescents were classified in OW1, OW2, and OW3, respectively, based on overweight screening criteria. Comparisons of subjects in the overweight and normal WT groups and between overweight groups are shown in Table 2. WT, WTz, BMI, and BMIz were greater among subjects in all three overweight groups compared to those in the normal WT group. However, HT of the subjects did not differ between the three groups. This indicated that subjects in the overweight groups exhibited higher WT and BMI without HT difference. On comparison of overweight groups, significant differences were observed in BMI and BMIz between OW1 and OW3 boys and girls. There was no significant difference in BMIz between OW2 and OW3 in either boys or girls.

The respective kappa values of each overweight group according to sex and age is shown in Table 3. The kappa values were 0.798 , 0.710, and 0.891 for OW1 and OW2, OW1 and OW3, and OW2 and OW3, respectively. Among the three comparisons, the most significant agreement was found in the OW2 and OW3 groups, especially in boys. The kappa values differed based on age and sex, were higher in boys than in girls, and were lower in mid-adolescents compared to late-adolescents.

In addition, as seen in the diagram of the degree of agreements, all three comparisons show substantial agreements (Fig. 1A-C). Furthermore, when the obesity group was included in the diagram of OW1 and OW3 (Fig. 1D), only one girl belonged to the OW1 and obesity group but not to the OW3 group. Her characteristics were as follows: HT, $157 \mathrm{~cm}$; WT, $59 \mathrm{~kg}$; BMI, $24 \mathrm{~kg} / \mathrm{m}^{2}$; HTz, 1.88; WTz, 2.15; and BMIz, 1.72. Only one boy belonged to the
OW3 group but not to the OW1 and obesity groups. His characteristics were as follows: HT, $170 \mathrm{~cm}$; WT, $74 \mathrm{~kg}$; BMI, $25 \mathrm{~kg} / \mathrm{m}^{2}$;

Table 3. The respective kappa values of OW1 and OW2, OW1 and OW3, and OW2 and OW3 based on sex and age

\begin{tabular}{|c|c|c|c|}
\hline Variable & OW1 and OW2 & OW1 and OW3 & OW2 and OW3 \\
\hline \multicolumn{4}{|l|}{ Sex } \\
\hline Boy & 0.813 & 0.770 & 0.955 \\
\hline Girl & 0.778 & 0.621 & 0.794 \\
\hline Total & 0.798 & 0.710 & 0.891 \\
\hline \multicolumn{4}{|l|}{ Age (yr) } \\
\hline \multicolumn{4}{|l|}{ Boy } \\
\hline $10(n=74)$ & 0.789 & 0.789 & 1.000 \\
\hline $11(n=69)$ & 0.742 & 0.742 & 1.000 \\
\hline $12(n=70)$ & 0.900 & 0.844 & 0.944 \\
\hline $13(n=53)$ & 0.655 & 0.655 & 1.000 \\
\hline $14(n=71)$ & 0.743 & 0.546 & 0.777 \\
\hline $15(n=45)$ & 0.897 & 0.776 & 0.877 \\
\hline $16(n=45)$ & 0.795 & 0.739 & 0.942 \\
\hline $17(n=53)$ & 0.922 & 0.922 & 1.000 \\
\hline $18(n=41)$ & 1.000 & 1.000 & 1.000 \\
\hline \multicolumn{4}{|l|}{ Girl } \\
\hline $10(n=64)$ & 0.269 & 0.142 & 0.660 \\
\hline $11(n=61)$ & 0.692 & 0.534 & 0.816 \\
\hline $12(n=40)$ & 0.756 & 0.660 & 0.895 \\
\hline $13(n=61)$ & 0.850 & 0.536 & 0.663 \\
\hline $14(n=59)$ & 0.869 & 0.679 & 0.679 \\
\hline $15(n=43)$ & 0.807 & 0.691 & 0.876 \\
\hline $16(n=43)$ & 0.919 & 0.909 & 0.830 \\
\hline $17(n=40)$ & 1.000 & 0.787 & 0.787 \\
\hline $18(n=33)$ & 0.914 & 0.820 & 0.904 \\
\hline
\end{tabular}

OW1 is a group with $\mathrm{BMI}>85$ th percentile for age and sex, OW2 is a group with weight for height $>85$ th percentile, and OW3 is a group with weight $>120 \%$ of ideal for height.

$\mathrm{OW}$, overweight; $\mathrm{BMI}$, body mass index.
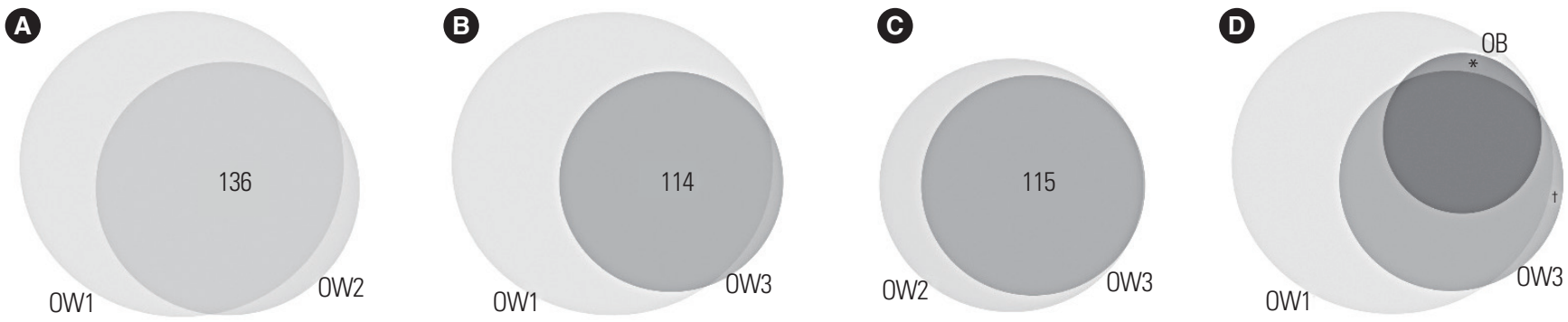

Figure 1. Diagrams of the degree of agreement between (A) OW1 and OW2, (B) OW1 and OW3, and (C) OW2 and OW3. There is substantial agreement in all three comparisons. Totals of 188, 139, and 115 adolescents were classified into the respective OW1, OW2, and OW3 groups. The number of overlapping adolescents is shown in the figure. (D) The diagram showing agreement among the OW1, OW3, and OB groups. * One adolescent belongs to the OW1 and obesity groups but not to the OW3 group (marked with the number sign. ${ }^{\dagger}$ Another adolescent only belongs to the OW3 group but not to the OW1 and obesity groups. OW, overweight group; OB, obesity group. $\mathrm{OW} 1$ is a group with $\mathrm{BMI}>85$ th percentile for age and sex, OW2 is a group with weight for height $>85$ th percentile, and OW3 is a group with weight $>120 \%$ of ideal for height. An obesity group is a group with $\mathrm{BMI}>95$ th percentile for age and sex. 
HTz, -0.44; WTz, 0.92; and BMIz, 1.17.

When comparing subjects in the overweight groups (OW1 and OW3) with those in the obesity group (BMI > 95th percentile for age and sex), there were significant differences in WT, WTz, BMI, and BMIz in the obesity and OW3 groups (Table 4). BMI and BMIz tended to increase in the order of OW1, OW3, and obesity groups. In addition, subjects (especially girls) in the OW3 group exhibited a lower HTz value compared to those in the other groups. The comparison of girls in the OW1 and OW3 groups revealed a significant difference $(P<0.05)$ in HTz values. A detailed comparison based on age revealed that the $\mathrm{Hz}$ value tended to decrease with age (Supplementary Table 1).

Table 4. Comparisons between the overweight (OW1 and OW3) and obesity groups

\begin{tabular}{|c|c|c|c|}
\hline Variable & OW1 & OW3 & Obesity \\
\hline Total & $(n=188)$ & $(n=115)$ & $(n=63)$ \\
\hline Age (yr) & $13.3 \pm 2.5$ & $13.7 \pm 2.7$ & $13.7 \pm 2.5$ \\
\hline $\mathrm{HT}(\mathrm{cm})$ & $160.1 \pm 11.2$ & $159.8 \pm 11.9$ & $161.7 \pm 9.5$ \\
\hline WT $(k g)^{\dagger}$ & $66.6 \pm 14.3$ & $70.0 \pm 15.4$ & $75.5 \pm 14.1$ \\
\hline BMI $\left(\mathrm{kg} / \mathrm{m}^{2}\right)^{*, \dagger}$ & $25.7 \pm 2.9$ & $27.0 \pm 2.8$ & $28.6 \pm 2.7$ \\
\hline$H T z^{*}$ & $0.95 \pm 1.13$ & $0.63 \pm 1.17$ & $0.88 \pm 1.18$ \\
\hline $\mathrm{WTz}^{\dagger}$ & $1.73 \pm 0.59$ & $1.81 \pm 0.68$ & $2.19 \pm 0.59$ \\
\hline$B M l z^{*,+}$ & $1.61 \pm 0.45$ & $1.82 \pm 0.44$ & $2.11 \pm 0.39$ \\
\hline Boy & $(n=108)$ & $(n=75)$ & $(n=36)$ \\
\hline Age (yr) & $13.2 \pm 2.5$ & $13.4 \pm 2.7$ & $13.5 \pm 2.5$ \\
\hline $\mathrm{HT}(\mathrm{cm})$ & $161.8 \pm 13.1$ & $161.0 \pm 13.8$ & $164.0 \pm 11.2$ \\
\hline $\mathrm{WT}(\mathrm{kg})^{\dagger}$ & $69.2 \pm 15.7$ & $71.1 \pm 17.0$ & $78.4 \pm 15.4$ \\
\hline BMI $\left(\mathrm{kg} / \mathrm{m}^{2}\right)^{*, \dagger}$ & $26.1 \pm 2.6$ & $26.9 \pm 2.7$ & $28.8 \pm 2.2$ \\
\hline $\mathrm{HTz}$ & $0.98 \pm 1.10$ & $0.79 \pm 1.18$ & $1.05 \pm 1.21$ \\
\hline $\mathrm{WTz}^{\dagger}$ & $1.69 \pm 0.56$ & $1.77 \pm 0.64$ & $2.14 \pm 0.55$ \\
\hline$B M l z^{*, t}$ & $1.57 \pm 0.39$ & $1.72 \pm 0.36$ & $2.02 \pm 0.27$ \\
\hline Girl & $(n=80)$ & $(n=40)$ & $(n=27)$ \\
\hline Age (yr) & $13.4 \pm 2.5$ & $14.3 \pm 2.4$ & $13.9 \pm 2.4$ \\
\hline $\mathrm{HT}(\mathrm{cm})$ & $157.9 \pm 7.6$ & $157.4 \pm 6.7$ & $158.5 \pm 5.3$ \\
\hline $\mathrm{WT}(\mathrm{kg})^{*}$ & $63.2 \pm 11.3$ & $67.9 \pm 11.9$ & $71.5 \pm 11.3$ \\
\hline BMI $\left(\mathrm{kg} / \mathrm{m}^{2}\right)^{*}$ & $25.2 \pm 3.2$ & $27.2 \pm 3.2$ & $28.3 \pm 3.2$ \\
\hline$H T z^{*}$ & $0.90 \pm 1.18$ & $0.33 \pm 1.11$ & $0.65 \pm 1.13$ \\
\hline $\mathrm{WTz}$ & $1.79 \pm 0.62$ & $1.90 \pm 0.76$ & $2.25 \pm 0.64$ \\
\hline $\mathrm{BMlz}^{*}$ & $1.66 \pm 0.52$ & $2.00 \pm 0.53$ & $2.23 \pm 0.48$ \\
\hline
\end{tabular}

OW1 is a group with BMI $>85$ th percentile for age and sex, OW3 is a group with weight $>120 \%$ of ideal for height, and an obesity group is a group with $\mathrm{BMI}>95$ th percentile for age and sex.

*Statistically significant $P<0.05$ between $0 \mathrm{~W} 1$ and $0 \mathrm{~W} 3$; 'Statistically significant $P<0.05$ between the obesity group and OW3.

$\mathrm{OW}$, overweight; $H T$, height; WT, weight; $B M I$, body mass index; $H T z$, z score of $H T$; $\mathrm{WT} z, \mathrm{z}$ score of $\mathrm{WT} ; \mathrm{BM} \mathrm{z}$, $\mathrm{z}$ score of $\mathrm{BMl}$.

\section{DISCUSSION}

The result of this study showed substantial agreement among the three overweight screening criteria, consistent with previous studies. ${ }^{6,7}$ In comparison of agreement between overweight groups (Table 3), the kappa value between OW1 and OW3 (0.710) was lower than that between OW2 and OW3 (0.891). There was variability in agreement according to age and sex, and the lowest kappa value was in mid-adolescents at approximately the age of peak HT increase (Table 3), 13.5 years in boys and 11.5 years in girls. ${ }^{10}$

In this study, BMI, WT for HT, and ideal body WT were tested as overweight indexes. BMI is a widely accepted screening index for overweight (BMI above 85th percentile) and obesity (BMI above 95th percentile), although the criteria used to assess these states in children and adolescents vary widely. ${ }^{11}$ In Classification and Diagnosis of Diabetes 2019 published by the American Diabetes Association, BMI was the only parameter used for screening type 2 diabetes in asymptomatic children and adolescents. ${ }^{12}$

Although BMI is used widely as a surrogate measure of adiposity, values in children should be interpreted with caution. BMI is a good indicator for relatively obese children but not for thinner children. ${ }^{13,14}$ Many Asians can be classified as normal WT but with obesity based on body composition and fat distribution. ${ }^{15}$ Due to the limitations of BMI, reference values for body composition components have been produced using various techniques, and the use of body composition charts for children through a personalized therapeutic approach has increased. ${ }^{15}$

Obesity-related health risks, including diabetes, are likely to be increased when OW3 is considered as the overweight screening criterion, owing to the higher number of missed adolescents (Table 2). Although the OW1 and OW3 criteria demonstrated substantial agreement, the differences in BMI and BMIz should be noted. The OW1 criterion should be used for screening to include more children and adolescents by focusing on the variability of individual growth.

One girl, who belonged to the OW1 and obesity groups but not to the OW3 group (Fig. 1D), had high WT but was relatively tall. Considering that the OW3 criterion is based on the ideal WT for HT, the taller is the individual, the greater is the ideal body WT. Therefore, the girl had a largely ideal body WT for HT and would 
not be considered overweight based on the OW3 criterion. However, if the OW1 criterion was considered, the girl would have been within the screening range and subjected to individual evaluation. The girl's BMI value was classified as obesity, showing the limitations of the OW3 criterion.

An adolescent might or might not be overweight depending on the criterion applied to their HT and WT. This indicates the importance of an assessment that reflects individual growth patterns and physical conditions. Although there is one adolescent in this comparison, more adolescents would be excluded from screening for obesity-related morbid diseases when targeting the entire population. When analyzing the HT and WT of each adolescent classified as overweight, some adolescents are short and overweight, while others are tall and overweight. Individualized evaluations of each overweight adolescent based on WT status scaling to HT is required.

Obese children tend to be taller than their normal-WT counterparts during pre-puberty. ${ }^{16}$ However, overall HT gain from pre-puberty to adult HT was lower in obese children compared to normal-WT children. ${ }^{16}$ In addition, after the age of peak HT increase, near final adult HT, the impact of HT on BMI is reduced, allowing for WT to have a greater influence. ${ }^{17,18}$ During puberty, rapid WT gain with growth acceleration or deceleration in obese children seems to affect the OW diagnosis and could result in differences in kappa values according to age and sex (Table 3). The lowest kappa value occurred at the age of 14 in boys and 11 in girls, which is the period of peak HT increase.

The prevalence of obesity could differ according to the criteria of OW. According to the Student Health Examination Sample Statistics from the Ministry of Education of Korea, one student in four was obese or overweight in $2018 .{ }^{19}$ As the criteria changed, the prevalence increased. For example, the prevalence of obesity in Korean students was $16.5 \%$ in a 2016 statistics report (based on OW 3$)^{20}$ but changed to $22.9 \%$ after being re-analyzed using OW1 in a 2018 statistics report. ${ }^{19}$ Overweight criteria were changed in 2018 from OW3 to OW1 to reflect the global trend as shown by World Health Organization and Organisation for Economic Co-operation and Development statistics. $^{21,22}$ Increasing prevalence based on criteria change leads to increases in the cost of testing for co-morbidities in adolescents. However, it is a small cost compared to the socio-economic burden caused by chronic diseases such as hypertension and diabetes. ${ }^{23}$

Other important factors should be considered in addition to evaluating HT and WT, such as birth WT, parents' HT and WT, family history, and medications being taken. ${ }^{24}$ The reason for considering birth WT is that metabolic capacity depends on whether the individual was small for gestational age. ${ }^{25,26}$ Compared to those who have normal birth WT, low birth WT is associated with low lean mass, which reduces metabolic capacity in adolescence and adulthood. ${ }^{27}$ Rapid catch-up growth increases fat mass rather than lean mass, which manifests as metabolic load..$^{28,29}$ Consequently, the greatest disease risk is observed in those who are born as small for gestational age and become overweight because they impose a large load on a small capacity. ${ }^{30,31}$

Identification of crucial periods for childhood and adolescent obesity could be useful for planning prevention measures. BMI charts can be used to monitor individual development, which can help assess individual changes and health risks. After the first 2 years of life involving rapid growth, the BMI decreases to a minimum around 6 years of age before increasing again, called the adiposity rebound. ${ }^{17}$ An early adiposity rebound is associated with increased risk of overweight. ${ }^{32}$ In addition, individualized therapeutic approaches are required for each child and adolescent, along with recommendations for lifestyle changes. ${ }^{33,34}$ For example, recent studies have shown therapeutic effects of metformin, a glucose-lowering drug commonly prescribed to diabetic patients. ${ }^{35,36}$ Some studies have shown significant reduction in BMI, body WT, and waist circumference after administration of metformin..$^{37,38}$

In conclusion, active assessment of overweight status using OW1 is appropriate to include a larger number of adolescents and focus on the variability of individual growth and disease risk, even though substantial agreement was found among three overweight screening criteria. Since the purpose of screening tests in adolescents is to detect overweight and obesity at an early stage and prevent disease, ${ }^{39,40}$ overweight adolescents should be assessed for individualized disease risks, including family history, birth WT, medical conditions, and medication use.

\section{CONFLICTS OF INTEREST}

Sochung Chung has worked as an editorial board member for the 
journal since 2013. However, she was not involved in the peer reviewer selection, evaluation, or decision-making process of this article.

\section{ACKNOWLEDGMENTS}

This study was presented as a poster at the 2019 ICOMES \& AOCO (International Congress on Obesity and Metabolic Syndrome \& Asia-Oceania Conference on Obesity).

\section{AUTHOR CONTRIBUTIONS}

Study concept and design: all authors; acquisition of data: SC; analysis and interpretation of data: JYH; drafting of the manuscript: JYH; critical revision of the manuscript: all authors; statistical analysis: JYH; administrative, technical, or material support: SC; and study supervision: SC.

\section{REFERENCES}

1. Han JC, Lawlor DA, Kimm SY. Childhood obesity. Lancet 2010;375:1737-48.

2. Kim JH, Moon JS. Secular trends in pediatric overweight and obesity in Korea. J Obes Metab Syndr 2020;29:12-7.

3. Güngör NK. Overweight and obesity in children and adolescents. J Clin Res Pediatr Endocrinol 2014;6:129-43.

4. Kumar S, Kelly AS. Review of childhood obesity: from epidemiology, etiology, and comorbidities to clinical assessment and treatment. Mayo Clin Proc 2017;92:251-65.

5. Castorani V, Polidori N, Giannini C, Blasetti A, Chiarelli F. Insulin resistance and type 2 diabetes in children. Ann Pediatr Endocrinol Metab 2020;25:217-26.

6. American Diabetes Association. (2) Classification and diagnosis of diabetes. Diabetes Care 2015;38 Suppl:S8-16.

7. American Diabetes Association. Type 2 diabetes in children and adolescents. Pediatrics 2000;105(3 Pt 1):671-80.

8. Park HW, Yoo HY, Kim CH, Kim H, Kwak BO, Kim KS, et al. Reference values of body composition indices: the Korean National Health and Nutrition Examination Surveys. Yonsei Med J 2015;56:95-102.

9. Moon JS, Lee SY, Nam CM, Choi JM, Choe BK, Seo JW, et al. 2007 Korean National Growth Charts: review of developmental process and an outlook. Korean J Pediatr 2008;51:1-25.

10. Tanner JM, Davies PS. Clinical longitudinal standards for height and height velocity for North American children. J Pediatr 1985; 107:317-29.

11. Dietz WH, Bellizzi MC. Introduction: the use of body mass index to assess obesity in children. Am J Clin Nutr 1999;70: 123S-125S.

12. American Diabetes Association. 2. Classification and Diagnosis of Diabetes: standards of medical care in diabetes-2019. Diabetes Care 2019;42(Suppl 1):S13-28.

13. Maynard LM, Wisemandle W, Roche AF, Chumlea WC, Guo SS, Siervogel RM. Childhood body composition in relation to body mass index. Pediatrics 2001;107:344-50.

14. Freedman DS, Wang J, Maynard LM, Thornton JC, Mei Z, Pierson RN, et al. Relation of BMI to fat and fat-free mass among children and adolescents. Int J Obes (Lond) 2005;29:1-8.

15. Chung S. Body composition analysis and references in children: clinical usefulness and limitations. Eur J Clin Nutr 2019;73: 236-42.

16. De Leonibus C, Marcovecchio ML, Chiavaroli V, de Giorgis T, Chiarelli F, Mohn A. Timing of puberty and physical growth in obese children: a longitudinal study in boys and girls. Pediatr Obes 2014;9:292-9.

17. Eriksson JG, Forsén T, Tuomilehto J, Osmond C, Barker DJ. Early adiposity rebound in childhood and risk of type 2 diabetes in adult life. Diabetologia 2003;46:190-4.

18. Chung S. Body mass index and body composition scaling to height in children and adolescent. Ann Pediatr Endocrinol Metab 2015;20:125-9.

19. Ministry of Education. 2018 Korean student health examination sample statistics [Internet]. Sejong: Ministry of Education; 2019 [cited 2021 Jul 27]. Available from: https://www.moe. go.kr/boardCnts/view.do?boardID=294\&boardSeq=77144\& lev $=0 \&$ searchType $=$ null \&statusYN $=W \&$ page $=1 \& s=$ moe $\& \mathrm{~m}$ $=020402 \&$ жртуре $=\mathrm{N}$

20. Ministry of Education. 2016 Korean student health examination sample statistics [Internet]. Sejong: Ministry of Education; 2017 [cited $2021 \mathrm{Jul} 27$ ]. Available from: https://www. moe.go.kr/boardCnts/view.do?boardID $=294 \&$ boardSeq $=70$ 
$517 \&$ lev $=0 \&$ searchType $=$ null \&status $Y N=C \&$ page $=89 \& s=\mathrm{m}$ oe\&m $=0501 \&$ opType $=\mathrm{N}$

21. OECD. Obesity update 2017 [Internet]. Paris: OECD; 2017 [cited 2021 Jul 27]. Available from: https://www.oecd.org/ health/health-systems/Obesity-Update-2017.pdf

22. World Health Organization. Report of the commission on ending childhood obesity [Internet]. Geneva: World Health Organization; 2016 [cited $2021 \mathrm{Jul} 27]$. Available from: https:// www.who.int/publications/i/item/9789241510066

23. Committee of Childhood and Adolescence of Korean Society for the Study of Obesity. Obesity in children and adolescents. 3rd ed. Seoul: Korean Society for the Study of Obesity; 2019.

24. Sweeney B, Kelly AS, San Giovanni CB, Kelsey MM, Skelton JA. Clinical approaches to minimize iatrogenic weight gain in children and adolescents. Clin Obes 2021;11:e12417.

25. Wells JC. Maternal capital and the metabolic ghetto: an evolutionary perspective on the transgenerational basis of health inequalities. Am J Hum Biol 2010;22:1-17.

26. Hong YH, Chung S. Small for gestational age and obesity related comorbidities. Ann Pediatr Endocrinol Metab 2018;23: 4-8.

27. Yajnik CS, Fall CH, Coyaji KJ, Hirve SS, Rao S, Barker DJ, et al. Neonatal anthropometry: the thin-fat Indian baby: the Pune Maternal Nutrition Study. Int J Obes Relat Metab Disord 2003;27:173-80.

28. Joglekar CV, Fall CH, Deshpande VU, Joshi N, Bhalerao A, Solat V, et al. Newborn size, infant and childhood growth, and body composition and cardiovascular disease risk factors at the age of 6 years: the Pune Maternal Nutrition Study. Int J Obes (Lond) 2007;31:1534-44.

29. Cho WK, Suh BK. Catch-up growth and catch-up fat in children born small for gestational age. Korean J Pediatr 2016;59: 1-7.

30. Andersen LG, Angquist L, Eriksson JG, Forsen T, Gamborg M, Osmond C, et al. Birth weight, childhood body mass index and risk of coronary heart disease in adults: combined historical cohort studies. PLoS One 2010;5:e14126.
31. Wells JC, Pomeroy E, Walimbe SR, Popkin BM, Yajnik CS. The elevated susceptibility to diabetes in India: an evolutionary perspective. Front Public Health 2016;4:145.

32. Rolland-Cachera MF, Deheeger M, Maillot M, Bellisle F. Early adiposity rebound: causes and consequences for obesity in children and adults. Int J Obes (Lond) 2006;30 Suppl 4:S11-7.

33. Chung S. Therapeutic approaches to obesity and metabolic syndrome in children and adolescents. J Korean Med Assoc 2018;61:599-606.

34. Altman M, Wilfley DE. Evidence update on the treatment of overweight and obesity in children and adolescents. J Clin Child Adolesc Psychol 2015;44:521-37.

35. Ladeiras-Lopes R, Fontes-Carvalho R, Bettencourt N, Sampaio F, Gama V, Leite-Moreira A. Novel therapeutic targets of metformin: metabolic syndrome and cardiovascular disease. Expert Opin Ther Targets 2015;19:869-77.

36. Sadeghi A, Mousavi SM, Mokhtari T, Parohan M, Milajerdi A. Metformin therapy reduces obesity indices in children and adolescents: a systematic review and meta-analysis of randomized clinical trials. Child Obes 2020;16:174-91.

37. Evia-Viscarra ML, Rodea-Montero ER, Apolinar-Jiménez E, Muñoz-Noriega N, García-Morales LM, Leaños-Pérez C, et al. The effects of metformin on inflammatory mediators in obese adolescents with insulin resistance: controlled randomized clinical trial. J Pediatr Endocrinol Metab 2012;25:41-9.

38. Freemark M, Bursey D. The effects of metformin on body mass index and glucose tolerance in obese adolescents with fasting hyperinsulinemia and a family history of type 2 diabetes. Pediatrics 2001;107:E55.

39. Hanson MA, Gluckman PD. Early developmental conditioning of later health and disease: physiology or pathophysiology? Physiol Rev 2014;94:1027-76.

40. Nittari G, Scuri S, Petrelli F, Pirillo I, di Luca NM, Grappasonni I. Fighting obesity in children from European World Health Organization member states: epidemiological data, medicalsocial aspects, and prevention programs. Clin Ter 2019;170: e223-30. 